\title{
In vitro assessment of reproductive toxicity of cigarette smoke and deleterious consequences of maternal exposure to its constituents
}

\author{
Shao-Chin $\mathrm{Wu}^{1}$, Min Liu*1,2 \\ ${ }^{1}$ Department of Life Science, Chinese Culture University, Taipei, Republic of China \\ 2 Graduate Institute of Biotechnology, Chinese Culture University, Taipei, Republic of China
}

\begin{abstract}
Cigarette smoke is known to be a serious health risk factor and considered reproductively toxic. In the current study, we investigated whether constituents of cigarette smoke, pyrazine, 2-ethylpyridine, and 3-ethylpyridine, adversely affect reproductive functioning such as oocyte maturation and sperm capacitation. Our findings indicated that three smoke components were involved in retardation of oocyte maturation in a dose-dependent manner and the lowest-observed-adverse-effect level (LOAEL) was determined to be $10^{-10} \mathrm{M}$. However, individual smoke components administrated at the LOAEL did not attenuate oocyte maturation, demonstrating that all three toxicants were equally required for the observed growth impairment. When exposed to all three components at $10^{-10} \mathrm{M}$ during in vitro capacitation, murine sperm lost forward progression and were unable to show adequate hyperactivation, which is indicative of the incompletion of the capacitation process. Only sperm administrated with 3-ethylpyridine alone showed significant reduction in capacitation status, suggesting the chemical is the one responsible for disrupting sperm capacitation. Taken together, this is the first report that documents the effect of cigarette smoke components on oocyte maturation and sperm capacitation. The present findings demonstrate the adverse effects of smoke constituents of mammalian reproduction and the differences in sensitivity to smoke components between male and female gametes. Since both processes take place in the female reproductive system, our data provide new insights into deleterious consequences of maternal exposure to cigarette smoke.
\end{abstract}

Key words: cigarette smoke, oocyte maturation, reproductive toxicity, sperm capacitation

\section{INTRODUCTION}

Cigarette smoke (CS) is known to be a serious health risk factor and is involved in the development and progression of human diseases such as multiple types of cancer, heart disease, strokes, emphysema, as well as many fetal and nonfetal problems. In addition, CS has been demonstrated to have deleterious impacts on reproductive health (Augood, Duckitt \& Templeton, 1998; Shiverick \& Salafia, 1999; Stillman, Rosenberg \& Sachs, 1986; Talbot, 2008). Cigarette smoke is generally defined into two types. Smoke generated from the burning tip of a cigarette, which is inhaled by the active smoker, is mainstream smoke (MS); whereas smoke produced from the burn-off end of the cigarette between puffs, which is directly released to the environment, is the sidestream smoke (SS). CS is a complex mixture that contains more than 4000 chemical components, including oxidants, free radicals, and carcinogens (Hecht, 2002; Smith et al., 2003). Many of these constituents have never been evaluated for their cellular toxicity and impact on different body systems. Prior studies using solid phase extraction cartridges and gas chromatography-mass spectrometry have identified pyridine and pyrazine derivatives in cigarette smoke, which are demonstrated to have adverse effects on human cultured cell proliferation, normal reproductive functioning in rodents, as well as embryo growth and angiogenesis in chick model (Ji et al., 2002; Melkonian et al., 2003; Riveles et al., 2003; Riveles et al., 2004; Yu et al., 2006). Among these characterized compounds, pyrazine and 2-ethylpyridine, which are found exlusively in SS and 3-ethylpyridine (which is present in both
MS and SS) are the most potent chemicals with the greatest inhibitory activity on cell proliferation in vitro and in vivo bioassay (Ji et al., 2002; Melkonian et al., 2003; Riveles et al., 2003). The serum concentrations of pyrazine, 2-ethylpyridine, and 3-ethylpyridine in active and passive smokers have not been determined; however, these three compounds are toxic at picmolar doses in vitro, as shown previously and it is likely that these molecules are present in vivo at high enough concentrations to cause toxicological effects on reproductive health.

Successful reproduction in mammalian females requires the stepwise completion of a series of complex interdependent events. Existing evidence indicates that this biological process is vulnerable to and may be impaired at many points by toxic substances such as cigarette smoke (Cooper \& Moley, 2008; Mattison, Nightingale \& Shiromizu, 1983; Shiverick \& Salafia, 1999; Soares \& Melo, 2008). Approximately 30\% of women at reproductive age smoke cigarettes in the United States (ASRM, 2004) and published works reveal that female reproductive functions can be compromised by smoke exposure at various targets. Maternal smoking during pregnancy is best known to be associated with adverse pregnancy outcomes, including low birth weight, premature delivery, spontaneous abortion, as well as perinatal mortality and ectopic pregnancy (Ahluwalia, Grummer-Strawn \& Scanlon, 1997; Ananth, Savitz \& Luther, 1996; Andersen \& Hermann, 1984; Mattison et al., 1989; Wang et al., 1997). Although female smoking has been shown to deleteriously impede ovarian, uterine, and placental functioning (Shiverick \& Salafia, 1999), the targets of CS in nonpregnant females are not as well addressed. Interestingly, 
prior studies have shown that cigarette smoke-associated impairment in mammalian oviducts are induced by affecting their ciliary-beat frequency and adhesion property, which are both crucial in oviductal pick-up of oocyte upon ovulation (Knoll et al., 1995; Knoll \& Talbot, 1998; Riveles et al., 2003; Riveles et al., 2004; Riveles et al., 2007). In addition, follicle loss is evident in mice when exposed to CS (Tuttle, Stampfli $\&$ Foster, 2009). Ovotoxicants such as polycyclic aromatic hydrocarbons $(\mathrm{PAH})$ in cigarette smoke has been shown to be responsible for oocyte loss in exposed animals (Mattison et al., 1989). One of the PAH, benzo- $[a]$-pyrene, $(\mathrm{B}[a] \mathrm{P})$ is identified to attenuate rat follicle growth and reduce follicle diameter in a dose-dependent manner in vitro (Neal et al., 2007). A previous study reported that normal oocyte functioning is compromised by inhibiting cortical granule formation and the establishment of block to polyspermy when exposed to a major CS component nicotine (Longo \& Anderson, 1970). Cadmium, another toxicant found in cigarette smoke, has been noted to be associated with failure of progression of oocyte development (Thompson \& Bannigan, 2008). Despite these deleterious outcomes of CS exposure in females, cigarette smoke is well known to be reproductively toxic to males by decreasing sperm density and causing sperm abnormal morphology in smokers (Evans et al., 1981; Handelsman et al., 1984; Karagounis, Papanikolaou \& Zavos, 1985; Vogt, Heller \& Borelli, 1986). CS and its constituents have been documented to be associated with sperm damage such as DNA strand break (Fraga et al., 1996; Shen et al., 1997), DNA adducts (Potts et al., 1999), chromosomal abnormality (Robbins et al., 1997; Rubes et al., 1998; Yauk et al., 2007) and plasma membrane integrity (Belcheva et al., 2004). Transport in the female reproductive track (Hung et al., 2007) and sperm motility in human and model animals are also negatively affected when exposed to CS (Evans et al., 1981; Hung et al., 2007; Leoni et al., 2002; Polyzos et al., 2009; Ramlau-Hansen et al., 2007; Thompson \& Bannigan, 2008). Although CS is generally considered harmful and impairs reproductive functions both in males and females, the exact molecular and cellular mechanisms by which CS exerts its toxicological effects are rather elusive. Epidemiological research into the reproductive effects of cigarette smoke is limited to one shortcoming, which is that assessment of exposure is mostly based on self-reported questionnaire surveys. In contrast, in vivo and in vitro experimental models allow evaluation and investigation of the effects of CS and it specific constituents on general health, including reproduction. Assays carried out in vitro are advantageous, in which manipulation of the experimental regime and reproducible biological outcomes are possible (Talbot, 2008).

Based on the preceding discussion of cigarette smoke and related biological toxicity, it was to our great interest to examine the reproductive outcomes of exposure to cigarette smoke. The objective of this study was to utilize a mouse model to assess reproductive toxicity of cigarette smoke constituents in vitro, especially focused on female exposure to CS. A series of experiments were carried out to investigate whether functionally essential processes, such as oocyte maturation and sperm capacitation, are disrupted by cigarette smoke components. Finally, methodologies established in this study can potentially be used as in vitro models and developed into readily available assays to assess effects of cigarette smoke components and other environmental toxicants on reproduction.

\section{METHODS}

Chemicals and reagents

Chemicals used to make all media, polyvinylpyrrolidone (PVP), bovine serum albumin (BSA), paraformaldehyde, Triton-X 100, and follicle-stimulating hormone (FSH) were purchased from Sigma Chemical Company (St. Louis, MO). 4-(2-hydroxyethyl) piperazine-1-ethanesulphonic acid (HEPES) was purchased from Biobasic Inc. (Ontario, Canada). Light mineral oil was purchased from a certified local vendor. Minimum essential media (MEM) and fetal bovine serum (FBS) for in vitro oocyte maturation were purchased from Hyclone (Logan, UT). Whittingham solution was prepared fresh for sperm collection and in vitro capacitation (Whittingham, 1971). Earle's balance salt solution with $28.18 \mathrm{mM}$ of sodium bicarbonate and $24.98 \mathrm{mM}$ of HEPES free acid (EBSS-H) was made as previously described (Hoodbhoy et al., 2001). EBSS-H, $\mathrm{pH} 7.4$ supplemented with $0.2 \%$ of polyvinylpyrrolidone (EBSS-H/0.2\% PVP) was used for dissection and oocyte collection. Brinster $\mathrm{Ca} / \mathrm{Mg}$-free solution (Brinster, 1972) was used to collect germinal vesicle intact (GVI) oocytes.

Animals

Animal maintenance and usage were approved by the CCU IACUC. Male ICR mice of 6-12 weeks of age and 12-day old female mice were purchased from the National Taiwan University Experimental Animal Center (Taipei, Taiwan). Animals were housed with 14:10 light and dark cycle and fed water and rodent chow ad libitum.

\section{Gamete preparation}

Oocytes were handled under light mineral oil to maintain the $\mathrm{pH}$ and osmolarity of the solutions. For in vitro maturation, GVI oocytes ranging from 30 to $50 \mu \mathrm{m}$ were harvested from ovaries of 12-day old females by follicular puncture. For sperm collection, both the cauda epididymides and vas deferens were recovered in Whittingham medium, pH7.4 supplemented with $20 \mathrm{mM}$ HEPES (Whittingham medium-H). Tissues were minced and incubated in $5 \% \mathrm{CO} 2$ at $37^{\circ} \mathrm{C}$ for $10 \mathrm{~min}$ and released sperm from different mice were pooled.

\section{In vitro oocyte maturation (IVM)}

Germinal vesicle oocytes were incubated in MEM solution supplemented with $10 \%$ FBS and $100 \mathrm{mU} / \mathrm{mL}$ of FSH in 50 to $100 \mu \mathrm{L}$ droplets of culture medium under light mineral oil at $37^{\circ} \mathrm{C}$ in an atmosphere of $5 \% \mathrm{CO}_{2}$ in air (Coticchio et al., 2004; Picton et al., 2008). Samples were examined using an inverted Olympus IX71 phase-contrast microscope and images were taken daily for 3 days. Experiments were repeated independently three times in duplicates or triplicates with a total of 934 oocytes.

\section{In vitro sperm capacitation and hyperactivation assay}

Freshly isolated murine sperm were counted and adjusted to $1 \times 10^{6} \mathrm{cell} / \mathrm{ml}$ for all experiments. To capacitate sperm in vitro, samples were incubated in Whittingham medium$\mathrm{H} / 4 \% \mathrm{BSA}$ for 1 hour under light mineral oil at $37^{\circ} \mathrm{C}$ in 
$5 \% \mathrm{CO}_{2}: 95 \%$ air. Sperm capacitation status was assessed based on hyperactivation by the objective photographic method. Samples were first loaded to a counting chamber in a Neubauer haemocytometer and the sperm movement pattern was then recorded under capacitating conditions using an Olympus IX71 phase-contrast microscope and a cooled digital color camera optimally set for analysis. During the analysis, play-backs and zoom facilities were used. Since hyperactivation is a flagellar phenomenon (Mortimer, 1997), it is possible to visually assess hyperactivation based on sperm motility; flagellar movement patterns were evaluated for the enumeration of non-hyperactivated and hyperactivated sperm (Kulanand \& Shivaji, 2001; Wolf, Hagopian \& Ishijima, 1986). In brief, non-hyperactivated sperm showed a planar motility pattern, while hyperactivated sperm showed helical and circular motility patterns with erratic trajectories (Wolf et al., 1986). The flagellar curvature ratio (flagellar bending) was also used as a criterion and only ratio $<0.5$ was considered hyperactive (Aoki et al., 1994; Demott \& Suarez, 1992). For each experiment, >100 sperm cells were counted for each sample. The percentage of capacitated sperm was calculated by dividing total hyperactivated sperm by the total viable sperm. Experiments were performed in duplicate and repeated independently four times.

\section{Statistical analysis}

Results were expressed as mean percentage \pm SEM. Each experiment was repeated at least three times in duplicates or triplicates. All percentage data were transformed to the arcsine of their square roots (Sokal \& Rohlf, 1981) and were analyzed statistically using a one-way analysis of variance (ANOVA) followed by Dunnett's post-hoc test when results of the ANOVA were significant. In both the ANOVA and Dunnett's test, results were considered significant when $p \leq 0.05$.

\section{RESULTS}

Effect of cigarette smoke component(s) on the in vitro maturation of murine oocytes

In mammals, primordial follicles, which consist of a primary oocyte as well as granulose cells and basement membrane, develop in the fetuses. Follicles at this stage are present in the ovaries at birth and throughout early age in females. Beginning at puberty or sexually mature age, the follicles containing oocytes start to grow under the influence of FSH and other stimulating hormones, and subsequently develop into primary, secondary, and tertiary follicles prior to ovulation. Follicles at different developmental stages are generally distinguishable on the basis of oocyte size, zona pellucid size, and the number of granulose cells. Several lines of evidence show that cigarette smoke constituents affect reproduction at multiple steps during oogenesis, implantation, and throughout fetal growth (Mattison et al., 1983). For the purpose of this study, we hypothesized that the pre-ovulatory stage is a vulnerable time for developing oocytes and exposure to cigarette smoke components during this period interferes with growth. To experimentally test this hypothesis, germinal vesicle-intact oocytes (GVI), ranging from 30 to $50 \mu \mathrm{m}$ in size, were collected from 12-day old female pups and matured in the presence of pyrazine, 2-ethylpyridine, and 3-ethylpyridine in vitro. Normally, 10 days are required for murine oocytes to complete their maturation in vitro and become fertilizable (Picton et al., 2008; Sadeu \& Foster, 2010); however, we limited our total culture time to three days in order to investigate the reproductive toxicity of CS constituents on the early phase of oogenesis. Oocytes were left with follicular cells intact because it was not necessary to denude oocytes to evaluate growth status and the maintenance of oocyte-granulosa cell connection is generally considered beneficial for maturation (Barrett \& Albertini, 2009; Schroeder \& Eppig, 1984). In the initial series of experiment, follicles containing oocytes were administrated with tested smoke constituents, pyrazine, 2-ethylpyridine, and 3-ethylpyridine in combination, all at a final concentration of $10^{-6} \mathrm{M}, 10^{-10} \mathrm{M}$, or $10^{-12} \mathrm{M}$. The maturation status of oocytes was examined and presented as the percentage of growth, derived by dividing oocyte diameter on day 3 by oocyte diameter on day 0 (Fig. 1A). For the control group, the average percentage of oocyte growth was $11.4 \% \pm 1.8 \%$ on day 3 . A $10-$ fold reduction in oocyte maturation was observed in treated groups $\left(10^{-6} \mathrm{M}: 0.8 \% \pm 1.2 \% ; 10^{-10} \mathrm{M}: 0.5 \% \pm 0.9 \%\right)$. At the lowest tested dose $10^{-12} \mathrm{M}$, the percentage of oocyte growth was lower than that of control group $(7.1 \% \pm 0.9 \%)$ although a statistical difference could not be shown. In all experimental groups, the general morphology of oocytes was not altered by the administration of smoke components during in vitro maturation (Fig. 1B, representative light micrographs of oocytes cultured with cigarette smoke components at $10^{-10} \mathrm{M}$ ). To exclude the possibility that the growth retardation was attributed to cytotoxicity, oocyte viability was assessed using trypan blue exclusion assay and determined not be affected (data not shown). Taken together, our results indicate that the oocyte maturation process was significantly disrupted by cigarette smoke constituents and the lowest observed adverse effect level (LOAEL) of pyrazine, 2-ethylpyridine, and 3-ethylpyridine in combination for GVI oocyte was $10^{-}$ ${ }^{10} \mathrm{M}$. Next, to determine whether the reproductive toxicity we observed could be attributable to a particular tested chemical, in vitro maturation assays were carried out in the presence of individual smoke components alone at LOAEL $\left(10^{-10} \mathrm{M}\right)$. In all treated groups, oocyte growth was comparable to that of the control group (control: $7 \% \pm 1.1 \%$, pyrazine: $8.5 \% \pm$ $1.4 \%$, 2-ethylpyridine: $9.4 \% \pm 2.2 \%$, and 3-ethylpyridine: $6.7 \%$ $\pm 1.3 \%$ (Fig. 1C), suggesting that the molecular mechanism responsible for the observed growth retardation induced by smoke constituents is multifactorial and involves a number of components.

Effect of cigarette smoke component(s) on the viability and capacitation of murine sperm

In order for successful fertilization to occur, sperm has to undergo extratesticular maturation through the process termed capacitation to become fully fertile. Findings of this study show that cigarette smoke components adversely affected female reproduction by impeding oocyte maturation. It was to our great interest to determine whether the capacitation process, which normally takes place in the female reproductive track, is also a potential target of cigarette smoke during fertilization. To answer this question, we carried out in vitro capacitation assays in the presence of pyrazine, 2-ethylpyridine, 3-ethylpyridine alone, or in combination all at a final concentration of $10^{-10} \mathrm{M}$ since this is our the LOAEL 
at which oocyte maturation was attenuated by tested CS components. In the first set of experiment, sperm viability was assessed following in vitro capacitation. A slight reduction in sperm viability was observed (before capacitation: $67.5 \%$ $\pm 7.5 \%$ vs. after capacitation: $54.3 \% \pm 5.8 \%$ ); however, this change was not statistically significant. Since the number of viable sperm was sustained at a comparable level after capacitation, capacitated sperm group was then designated as the control for subsequent analysis. Our data showed that sperm viability in all treated groups was similar to that of the control group (control: $54.3 \% \pm 5.8 \%$, pyrazine: $52.1 \% \pm$ $5.0 \%$, 2-ethylpyridine: $56.6 \% \pm 7.0 \%$, 3-ethylpyridine: $55 \% \pm$ $4.5 \%$, in combination: $53.2 \% \pm 5.9 \%$, Fig. $2 \mathrm{~A}$ ), indicating that tested chemicals were not cytotoxic to sperm. To quantify sperm capacitation status, sperm hyperactive motility was evaluated since vigorous flagellar movement accompanies capacitated sperm in mammals (Kulanand \& Shivaji, 2001; Mortimer, 1997; Wolf et al., 1986). The number of hyperactive sperm prior to and following in vitro assays was enumerated and a 10-fold increase observed (before capacitation: $2.7 \%$ $\pm 1.5 \%$ vs. after capacitation: $29.6 \% \pm 4.35 \%$ ), confirming that our in vitro capacitation assays were successfully carried out. To determine whether CS components impede the capacitation process, sperm were exposed to pyrazine, 2-ethylpyridine, 3-ethylpyridine alone, or in combination. When sperm were capacitated in the presence of pyrazine or 2-ethylpyridine, the capacitation status was reduced although a statistical difference could not be shown (control: $29.6 \% \pm$ $4.4 \%$, pyrazine: $21.2 \% \pm 2.3 \%$, 2-ethylpyridine: $20.2 \% \pm 2.4 \%$, Fig. 2B). Interestingly, exposure to 3-ethylpyridine alone or to the mixture of smoke components containing this chemical resulted in a significant decrease in the number of capacitated sperm (3-ethylpyridine: $16.7 \% \pm 1.9 \%$, in combination: $13.0 \%$ $\pm 1.5 \%$, Fig. $2 \mathrm{~B}$ ). Taken together, our in vitro toxicological studies of pyrazine, 2-ethylpyridine, and 3-ethylpyridine demonstrated that smoke constituents deleteriously and differentially affected mammalian reproductive system. The cigarette smoke-induced toxicity we observed in sperm and oocytes was mediated by different smoke components.

\section{DISCUSSION}

In the current study, we investigated whether cigarette smoke constituents, pyrazine, 2-ethylpyridine, and 3-ethylpyridine, adversely affect reproductive functioning such as oocyte maturation and sperm capacitation, which both take place in the female reproductive system prior to fertilization. The present findings demonstrate that all three smoke components are collectively required and involved in retardation of oocyte maturation at a dose-dependent manner. The LOAEL of these smoke components inhibiting oocyte growth was determined to be at $10^{-10} \mathrm{M}$. However, individual smoke component administrated at this concentration did not affect oocyte maturation in vitro, suggesting that all three toxicants are equally responsible for the growth impairment we observed. When exposed to cigarette smoke components at the same concentration in vitro, the murine sperm lost forward progression and were unable to show adequate hyperactivation, which is indicative of the incompletion of capacitation process (Yamamoto et al., 1997). In addition, our data showed that only sperm administrated with 3-ethylpyridine and the mixture of all three smoke components showed defect in the ability to undergo hyperactivation, demonstrating that 3-ethylpyridine is the substance responsible for hampering sperm capacitation. Taken together, the present study shows that smoke constituents exert adverse effects on both male and female reproductive functioning. The findings are in agreement with the fact that cigarette smoke is associated with negative reproductive consequences and ultimately alters fertility. Finally, our data reveal that the reproductive toxicity and target of each tested smoke component are different when exposed to males and females.

This is the first report, to our knowledge, that documents the in vitro influence of cigarette smoke components on oocyte maturation and sperm capacitation. Since both biological processes take place inside the female reproductive system, our data provide new insights into deleterious consequences of maternal exposure to cigarette smoke. In addition, findings of this study reveal the difference in sensitivity to smoke components between sperm capacitation and oocyte maturation. Among all reproductive system targets, ovarian tissue is one of the most studied regarding cigarette smoke component exposure. A number of studies of patients undergoing assisted reproductive technology treatments showed a significant decrease in the number of retrieved oocytes from smokers (ElNemr et al., 1998; Fuentes et al.; Klonoff-Cohen et al., 2001; Motejlek et al., 2006; Van Voorhis et al., 1992; Weigert et al., 1999; Zitzmann et al., 2003). Moreover, accumulation of cigarette smoke components in ovarian follicles as well as in many other organs is evident, supported by a prior study of a major smoke constituent cadmium (Paszkowski, Clarke \& Hornstein, 2002). Results of toxicological evaluation of cigarette smoke constituents from this study may explain why reproductively assisted smokers have less retrievable oocytes since pyrazine, 2-ethylpyridine, and 3-ethylpyridine are also likely to accumulate in ovarian tissue and induce retardation of oocyte growth. Despite the fact that smoking is detrimental, the exact set of molecules responsible for the adverse effects of cigarette smoke remains poorly defined. In the present study, we have identified three new ovotoxicants, pyrazine, 2-ethylpyridine, and 3-ethylpyridine, in both MS and SS of cigarette smoke that are involved in delaying oocyte maturation. Moreover, 3-ethylpyridine is demonstrated to inhibit sperm acquiring hyperactive motility when tested in capacitation assay. Taken together, our experimental results not only reveal the sites of action for reproductive toxins in cigarette smoke using experimental animal models but also can be extrapolated to evaluate other human health risks in the future.

Data of this study suggest that different cellular and molecular mechanisms underlie the differential effects of individual cigarette smoke components on reproduction. Since it is possible but less probable that a single disrupted biological process is responsible for all our observed reproductive toxicity, we proposed several mechanisms that may explain the findings of this study. First, the impairment in oocyte maturation we observed most likely results from inhibition of cytoplasmic maturation initiated by induction of oxidative stress inside pre-ovulatory ovarian follicle (Paszkowski et al., 2002). This hypothesis is supported by studies demonstrating that increased oxidative stress or decreased antioxidative capacity is induced by cigarette smoke or its components (Fraga et al., 1996; Saleh et al., 2002; Shen et al., 1997). Second, granulosa are responsible for transferring signals such as FSH, 
as well as nutrients into and out of the oocyte and between follicle cells during folliculogenesis (Behrman et al., 1988; Fair, 2003; Kidder \& Mhawi, 2002; Zhuo \& Kimata, 2001). A previous study revealed that cigarette smoke compromised normal functions of granulosa cells and caused cell death in some cases (Bordel et al., 2006; Sinko et al., 2005; Tiemann, Pohland \& Schneider, 1996). Therefore, we could not rule out the possibility that oocyte maturation was perturbed due to interference of granulosa functioning. Aside from oocyte growth impairment, we also discovered that cigarette smoke constituents disrupt the murine sperm capacitation process. Several lines of evidence indicate that sperm membrane, as well as mitochondria integrity, are detrimentally damaged when sperm are submitted to cigarette smoke extract and cotinine (Hung et al., 2007; Sofikitis et al., 2000). We postulate that the observed capacitation impediment could be attributable to the loss of normal mitochondria activity since this organelle is essential in powering sperm hyperactivation. Ongoing studies designed to test these hypotheses and define the exact mechanisms(s) responsible for the reproductive toxicity of pyrazine, 2-ethylpyridine, and 3-ethylpyridine are currently in progress.

Cigarette smoke is composed of thousands of chemicals, which along with their metabolites must enter the circulatory system to reach target tissues to induce biological toxicity. Researchers have shown that the concentration of cigarette smoke components in the reproductive system or fluids is significantly higher than in serum (McLachlan et al., 1976; Neal, Zhu \& Foster, 2008; Paszkowski, 1998), indicating that smoke constituents accumulates in reproductive organs. For example, pregnant rabbits injected with nicotine accumulate five times or more of nicotine in uterine fluid than in plasma (Sasson et al., 1985). In humans, cervical fluid of female smokers has higher nicotine concentrations than in serum (Paszkowski, 1998). Similarly, cadmium has been demonstrated to concentrate in both follicular fluid and ovarian tissue (Varga et al., 1993). Although the serum concentrations of smoke components tested in this study in active and passive smokers have not been determined, these chemicals are reported to be reproductive toxic at picomolar dose in several studies (Ji et al., 2002; Melkonian et al., 2003; Riveles et al., 2003). Therefore, it is reasonable to assume that these molecules are present in vivo at high enough concentrations to exert toxicological effects. A study on cigarette smoke revealed that the concentrations of 2-ethylpyridine and 3-ethylpyridine in MS and SS range from 2 to $71 \mathrm{mg} / \mathrm{g}$ in the commercial cigarettes (Riveles et al., 2003). When the concentrations are compared to LOAEL determined in our study $\left(10^{-10} \mathrm{M}\right.$ or equivalent to $\left.10^{-5} \mathrm{mg} / \mathrm{g}\right)$, the LOAEL value is about 10,000 to 100 million times lower, suggesting that tested smoke constituents may actually exert greater effects on female smokers.

Prior studies of major cigarette smoke constituents, such as benzo-[a]-pyrene $(\mathrm{B}[a] \mathrm{P})$ and cadmium, have revealed that these chemicals impair normal oogenesis. For examples, the growth of rat follicles cultured in vitro was impeded by the presence of $\mathrm{B}[a] \mathrm{P}$ (Lodovici et al., 2004; Neal et al., 2007). Moreover, administration of this toxicant significantly reduced follicle diameter and attenuated FSH stimulated growth in a dose-dependent manner. A prior study also showed that $\mathrm{B}[a]$ $\mathrm{P}$ induced inhibition of antral follicle development (Sadeu \& Foster, 2010). Cadmium has been demonstrated to hinder germinal vesicle breakdown (Fort et al., 2002) and to reduce the percentage of oocytes undergoing normal developmental progression in vivo (Lienesch, Dumont \& Bantle, 2000). Interestingly, $\mathrm{B}[a] \mathrm{P}$ is detected in concentration ranging from 20 to 79ng per cigarette in SS and MS (Kaiserman \& Rickert, 1992) and 50-200ng of cadmium is estimated to be inhaled when cigarette is smoked (Elinder, 1985). Both $\mathrm{B}[a] \mathrm{P}$ and cadmium are much higher in amount in cigarette smoke than 2-ethylpyridine and 3-ethylpyridine, suggesting smoke components tested in this study are more toxic and potent in causing reproductive damages. Finally, a recent study reported that oocytes collected from female mice that were pre-exposed to cigarette smoke underwent full maturation to metaphase II, and their growth rates were similar to that of oocytes from non-exposed groups (Jennings et al., 2010). Since cigarette smoke was not administrated to these oocytes during the assay according to their experimental design, this may explain why the maturation rate did not appear to be affected by their smoking regimen.

Previously, a study of rhesus monkey sperm showed that exposure to cigarette smoke in vitro greatly affected their hyperactivation (Hung et al., 2007). Similarly, Sofikitis et al. demonstrated that cotinine, the major metabolite of nicotine, exerts a detrimental effect on human sperm ability to undergo capacitation evaluated by progressive motility assay, indicating that the machinery of capacitation was impaired (Sofikitis et al., 2000). Interestingly, both whole cigarette smoke extract and smoke metabolite cotinine did not affect sperm viability when assayed (Hung et al., 2007; Sofikitis et al., 2000) and the finding is consistent with our observation. Research on cigarette smoking also has revealed that capacity of exposed sperm to under acrosome reaction is greatly reduced (ElMulla et al., 1995; Evans et al., 1981), in agreement with the fact that smoke components deleterious affect the completion of capacitation as reported here. In addition, male mice exposed to cigarette smoke had differential sensitivity to MS and SS smoke, and only the latter one showed significantly reduction in their sperm mobility (Polyzos et al., 2009). In the present study, we specifically assessed the effect of three cigarette smoke constituents on sperm hyperactivation and demonstrated that only 3-ethylpyridine, which is found in both MS and SS smoke, inhibited sperm capacitation. It is possible that the amount of 3-ethylpyridine present in MS is insufficient to induce any effects when tested in vivo; however, the discrepancy between two studies needs to be experimentally resolved. Finally, exposure of mature mouse sperm in vitro to nicotine or cotinine apparently did not induce any observable effect in sperm motility as reported by Gandini et al. (Gandini et al., 1997). Here we report a novel sperm toxicant, 3-ethylpyridine, which adversely affects murine sperm progressive motility. Nevertheless, one should still keep in mind that direct extrapolation of cigarette smoke component between human and other animal models requires caution because cellular and molecular differences among different species can affect the experimental outcomes.

In the last few decades, the use of in vitro toxicology tests has been considered to be a practical tool for evaluating the risk for human health following exposure to certain harmful chemicals. Although an in vitro assay does not completely mimic the in vivo environment, it provides an excellent model to study reproductive toxicants in a time-, dose-, and stage-dependent manner. The major end points evaluated in most vitro cytotoxicity assays are the effect of tested agents 
on cell viability and cellular growth rates, as well as general mechanisms common to all cells. The use of in vitro model system described in this study enables one to evaluate not only the impact of cigarette smoke toxicants as well as other environemntal toxicants on general cellular functioning, but also on reproductive processes such as oocyte maturation and sperm capacitation. Moreover, our assay is rapid, inexpensive, and gives a quantitative evaluation of reproductive toxicity measured. Data collected using this methodology would be useful to inform the general publich about the deleterious consequences of female smoking and exposure to cigarette smoke, and may help campaigns for young women to quit smoking at reproductive age.

\section{ACKNOWLEDGEMENTS}

We are grateful to Zoe $\mathrm{Wu}$ and Stan Wang for their technical assistances in obtaining Figure 1. This study was supported by a research grant from the National Science Council and by grants from the Chinese Culture University.

\section{REFERENCES}

AHLUWALIA IB, GRUMMER-STRAWN L, SCANLON KS (1997) Exposure to environmental tobacco smoke and birth outcome: increased effects on pregnant women aged 30 years or older. Am J Epidemiol 146: 42-7.

ANANTH CV, SAVITZ DA, LUTHER ER (1996) Maternal cigarette smoking as a risk factor for placental abruption, placenta previa, and uterine bleeding in pregnancy. Am J Epidemiol 144: 881-9.
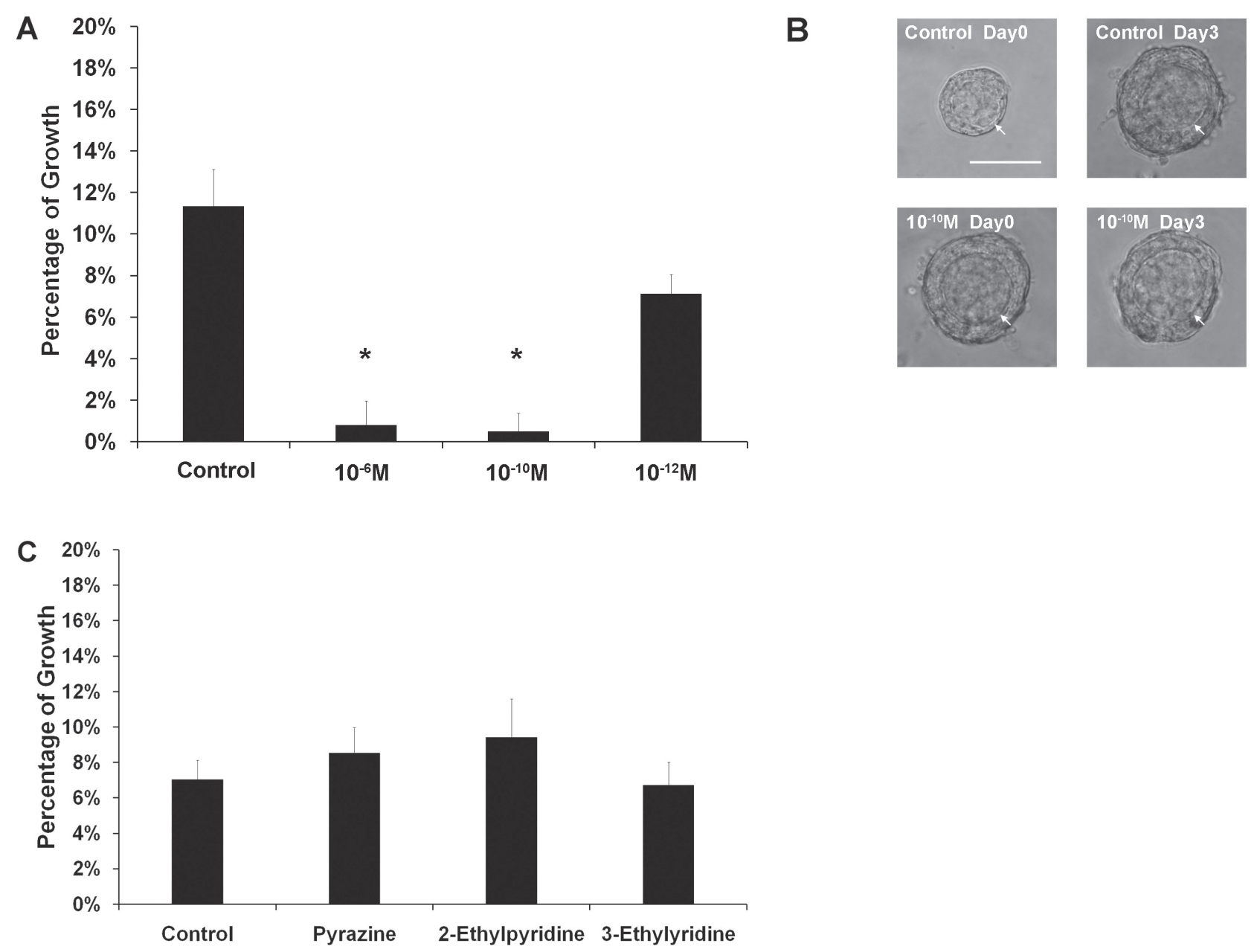

Figure 1: In vitro maturation of germinal vesicle intact oocyte in the present of cigarette smoke constituents. The growth status is presented as percentage of growth, which is derived by dividing oocyte diameter on day 3 by oocyte diameter on day 0 ( $A$, C). (A) Oocytes were matured in the presence of three tested cigarette smoke components (pyrazine, 2-ethylpyridine, and 3-ethylpyridine) all at a final concentration of $10^{-6} \mathrm{M}, 10^{-10} \mathrm{M}$, or $10^{-12} \mathrm{M}$. Control groups were not exposed to any tested chemicals. Experiments were repeated independently three times in duplicates or triplicates with a total of 637 oocytes $(\mathrm{N}=3)$. (B) Light micrographs of in vitro matured mouse oocytes in growing follicles (arrowed). Oocytes from both control and treated groups (with $10^{-10} \mathrm{M}$ of tested smoke constituents) were imaged on day 1 and day 3. Scale bar $=200 \mu \mathrm{m}$. (C) Oocytes were matured in the presence of individual smoke components at a final concentration of $10^{-10} \mathrm{M}$. Experiments were repeated independently three times with a total of 297 oocytes in duplicates or triplicates. $(\mathrm{N}=3)$ Results were expressed as mean percentage \pm SEM $(A, C)$. Statistical differences between control and treated groups were determined using an ANOVA followed by Dunnett's post-hoc test when results of the ANOVA were significant $(p<0.05)$. Experimental data sets that were significantly different from that of control group are labeled with an asterisk $\left(^{*}\right)$. 

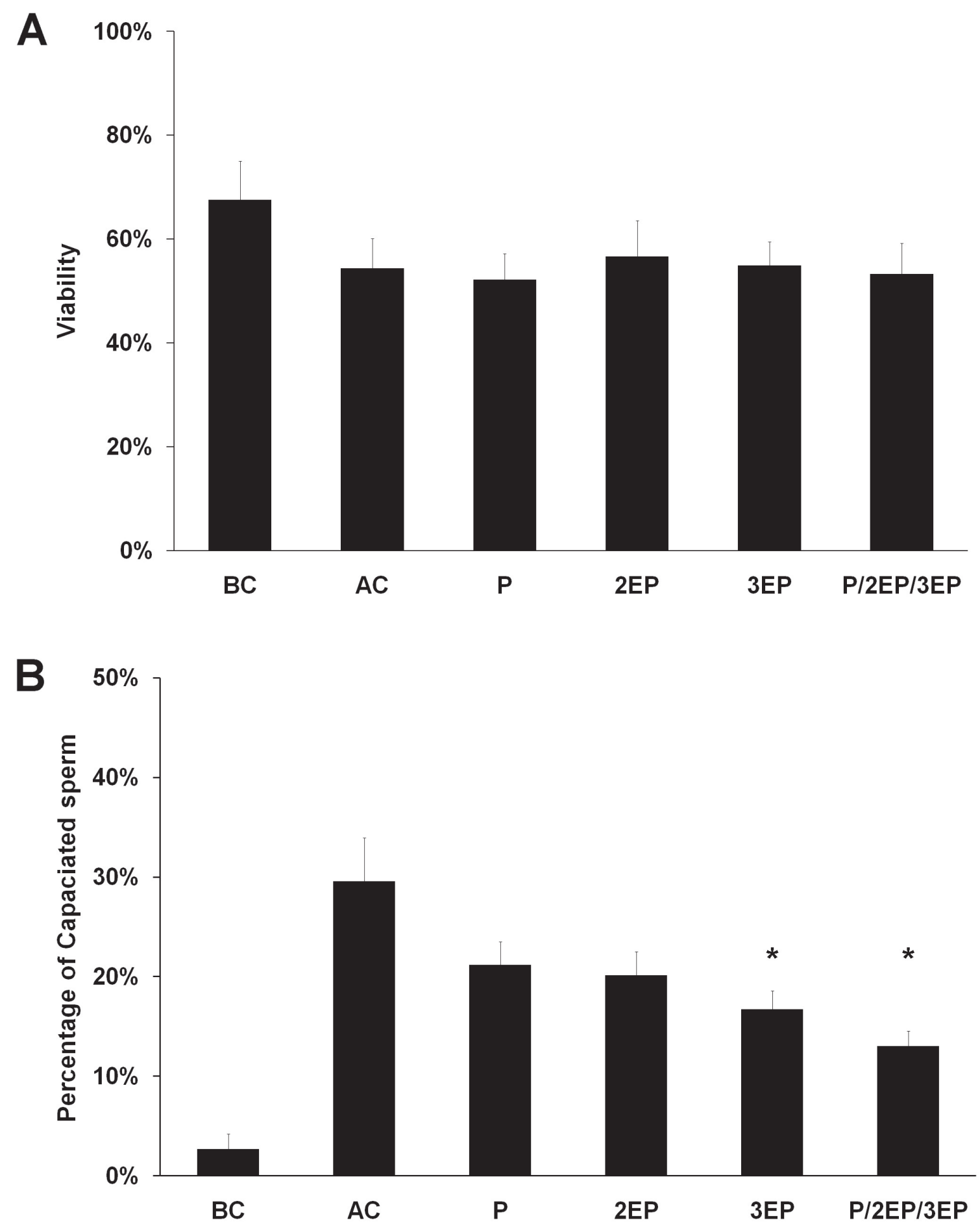

Figure 2: Assessment of the effects of cigarette smoke constituents on mouse sperm viability and capacitation. (A) Percentage of viable sperm of control and treated groups. Viability of freshly isolated sperm prior to capacitation was also shown to confirm that any significant difference observed between control and experimental groups was due to the experimental regime. (B) Percentage of capacitated sperm in control and treated groups. Capacitation status of freshly isolated sperm was compared to that of sperm that underwent in vitro capacitation to ensure that experimental conditions were optimized. Results were expressed as mean percentage \pm SEM. Statistical differences between control (after capacitation) and treated groups were determined using an ANOVA, followed by Dunnett's post-hoc test when the results of the ANOVA were significant $(p<0.05)$. Experimental data sets that were significantly different from that of control group are labeled with an asterisk $(*)$. BC $=$ before capacitation. $\mathrm{AC}=$ after capacitation; $\mathrm{P}=$ Pyrazine; $2 \mathrm{EP}=2$-ethylpyridine; $3 \mathrm{EP}=$ 3-ethylpyridine. Experiments were performed independently four times in duplicate and repeated $(\mathrm{N}=4)$. 
ANDERSEN KV, HERMANN N (1984) Placenta flow reduction in pregnant smokers. Acta Obstet Gynecol Scand 63: 707-9.

AOKI F, ISHIDA K, OKUNO M, KOHMOTO K (1994) Analysis of flagellar bending in hyperactivated hamster and mouse spermatozoa. J Reprod Fertil 101: 397-403.

ASRM (2004) Smoking and Infertility. Practice Committee of the American Society for Reproductive Medicine 81: 1181-1186.

AUGOOD C, DUCKITT K, TEMPLETON AA (1998) Smoking and female infertility: a systematic review and meta-analysis. Hum Reprod 13: 15329.

BARRETT SL, ALBERTINI DF (2009) Cumulus cell contact during oocyte maturation in mice regulates meiotic spindle positioning and enhances developmental competence. J Assist Reprod Genet 27: 29-39.

BEHRMAN HR, PRESTON SL, PELLICER A, PARMER TG (1988) Oocyte maturation is regulated by modulation of the action of FSH in cumulus cells. Prog Clin Biol Res 267: 115-35.

BELCHEVA A, IVANOVA-KICHEVA M, TZVETKOVA P, MARINOV M (2004) Effects of cigarette smoking on sperm plasma membrane integrity and DNA fragmentation. Int J Androl 27: 296-300.

BORDEL R, LASCHKE MW, MENGER MD, VOLLMAR B (2006) Nicotine does not affect vascularization but inhibits growth of freely transplanted ovarian follicles by inducing granulosa cell apoptosis. Hum Reprod 21: 610-7.

BRINSTER RL (1972) Cultivation of the mammalian embryo. In: Rothblat G, Cristofalo V (ed) Growth, Nutrition and Metabolism of Cells in Culture. New York: Academic Press, Inc. pp: 251-286.

COOPER AR, MOLEY KH (2008) Maternal tobacco use and its preimplantation effects on fertility: more reasons to stop smoking. Semin Reprod Med 26: 204-12.

COTICCHIO G, ROSSI G, BORINI A, GRONDAHL C, MACCHIARELLI G, FLAMIGNI C, FLEMING S, CECCONI S (2004) Mouse oocyte meiotic resumption and polar body extrusion in vitro are differentially influenced by FSH, epidermal growth factor and meiosis-activating sterol. Hum Reprod 19: 2913-8.

DEMOTT RP, SUAREZ SS (1992) Hyperactivated sperm progress in the mouse oviduct. Biol Reprod 46: 779-85.

ELINDER CG (1985) Cadmium: Uses, Occurrence, and Intake. In: Friberg L, Elinder C, Kjellstrom T, Nordberg G (ed) Cadmium and Health: A Toxicological and Epidemiological Appraisal Volume 1: Exposure, dose, and metabolism Boca Raton, FL: CRC Press. pp: 23-64.

ELMULLA KF, KOHN FM, ELBEHEIRY AH, SCHILL WB (1995) The effect of smoking and varicocele on human sperm acrosin activity and acrosome reaction. Hum Reprod 10: 3190-4.

ELNEMR A, ALSHAWAF T, SABATINI L, WILSON C, LOWER AM, GRUDZINSKAS JG (1998) Effect of smoking on ovarian reserve and ovarian stimulation in in-vitro fertilization and embryo transfer. Hum Reprod 13: 2192-8.

EVANS HJ, FLETCHER J, TORRANCE M, HARGREAVE TB (1981) Sperm abnormalities and cigarette smoking. Lancet 1: 627-9.

FAIR T (2003) Follicular oocyte growth and acquisition of developmental competence. Anim Reprod Sci 78: 203-16.

FORT DJ, MCLAUGHLIN DW, ROGERS RL, BUZZARD BO (2002) Effect of endocrine disrupting chemicals on germinal vesicle breakdown in Xenopus in vitro. Drug Chem Toxicol 25: 293-308.

FRAGA CG, MOTCHNIK PA, WYROBEK AJ, REMPEL DM, AMES BN (1996) Smoking and low antioxidant levels increase oxidative damage to sperm DNA. Mutat Res 351: 199-203.

FUENTES A, MUNOZ A, BARNHART K, ARGUELLO B, DIAZ M, POMMER R Recent cigarette smoking and assisted reproductive technologies outcome. Fertil Steril 93: 89-95.

GANDINI L, LOMBARDO F, LENZI A, CULASSO F, PACIFICI R, ZUCCARO P, DONDERO F (1997) The in-vitro effects of nicotine and cotinine on sperm motility. Hum Reprod 12: 727-33.

HANDELSMAN DJ, CONWAY AJ, BOYLAN LM, TURTLE JR (1984) Testicular function in potential sperm donors: normal ranges and the effects of smoking and varicocele. Int J Androl 7: 369-82.

HECHT SS (2002) Cigarette smoking and lung cancer: chemical mechanisms and approaches to prevention. Lancet Oncol 3: 461-9.

HOODBHOY T, DANDEKAR P, CALARCO P, TALBOT P (2001) p62/p56 are cortical granule proteins that contribute to formation of the cortical granule envelope and play a role in mammalian preimplantation development. Mol Reprod Dev 59: 78-89.

HUNG PH, BAUMBER J, MEYERS SA, VANDEVOORT CA (2007) Effects of environmental tobacco smoke in vitro on rhesus monkey sperm function. Reprod Toxicol 23: 499-506.
JENNINGS PC, MERRIMAN JA, BECKETT EL, HANSBRO PM, JONES KT (2010) Increased zona pellucida thickness and meiotic spindle disruption in oocytes from cigarette smoking mice. Hum Reprod 26: 878-84.

JI L, MELKONIAN G, RIVELES K, TALBOT P (2002) Identification of pyridine compounds in cigarette smoke solution that inhibit growth of the chick chorioallantoic membrane. Toxicol Sci 69: 217-25.

KAISERMAN MJ, RICKERT WS (1992) Carcinogens in tobacco smoke: benzo[a]pyrene from Canadian cigarettes and cigarette tobacco. Am J Public Health 82: 1023-6.

KARAGOUNIS CS, PAPANIKOLAOU NA, ZAVOS PM (1985) Semen parameters compared between smoking and nonsmoking men: smoking intensity and sem parameters. Infertility 8: 373.

KIDDER GM, MHAWI AA (2002) Gap junctions and ovarian folliculogenesis Reproduction 123: 613-20.

KLONOFF-COHEN H, CHU E, NATARAJAN L, SIEBER W (2001) A prospective study of stress among women undergoing in vitro fertilization or gamete intrafallopian transfer. Fertil Steril 76: 675-87.

KNOLL M, SHAOULIAN R, MAGERS T, TALBOT P (1995) Ciliary beat frequency of hamster oviducts is decreased in vitro by exposure to solutions of mainstream and sidestream cigarette smoke. Biol Reprod 53: 29-37.

KNOLL M, TALBOT P (1998) Cigarette smoke inhibits oocyte cumulus complex pick-up by the oviduct independent of ciliary beat frequency. Reproductive Toxicology 12: 57-68.

KULANAND J, SHIVAJI S (2001) Capacitation-associated changes in protein tyrosine phosphorylation, hyperactivation and acrosome reaction in hamster spermatozoa. Andrologia 33: 95-104.

LEONI G, BOGLIOLO L, DEIANA G, BERLINGUER F, ROSATI I, PINTUS PP, LEDDA S, NAITANA S (2002) Influence of cadmium exposure on in vitro ovine gamete dysfunction. Reprod Toxicol 16: 371-77.

LIENESCH LA, DUMONT JN, BANTLE JA (2000) The effect of cadmium on oogenesis in Xenopus laevis. Chemosphere 41: 1651-8.

LODOVICI M, AKPAN V, EVANGELISTI C, DOLARA P (2004) Sidestream tobacco smoke as the main predictor of exposure to polycyclic aromatic hydrocarbons. J Appl Toxicol 24: 277-81.

LONGO FJ, ANDERSON E (1970) The effects of nicotine on fertilization in the sea urchin, Arbacia punctulata. J Cell Biol 46: 308-25.

MATTISON DR, NIGHTINGALE MS, SHIROMIZU K (1983) Effects of toxic substances on female reproduction. Environ Health Perspect 48: 43-52.

MATTISON DR, PLOWCHALK DR, MEADOWS MJ, MILLER MM, MALEK A, LONDON S (1989) The Effect of Smoking on Oogenesis, Fertilization, and Implantation. Seminars in Reproductive Endocrinology 7: 291-304.

MCLACHLAN JA, DAMES NM, SIEBER SM, FABRO S (1976) Accumulation of nicotine in the uterine fluid of the six-day pregnant rabbit. Fertil Steril 27: 1204-13

MELKONIAN G, ECKELHOEFER H, WU M, WANG Y, TONG C, RIVELES $\mathrm{K}$, TALBOT P (2003) Growth and angiogenesis are inhibited in vivo in developing tissues by pyrazine and its derivatives. Toxicol Sci 75: 393401.

MORTIMER ST (1997) A critical review of the physiological importance and analysis of sperm movement in mammals. Hum Reprod Update 3: $403-$ 39.

MOTEJLEK K, PALLUCH F, NEULEN J, GRUMMER R (2006) Smoking impairs angiogenesis during maturation of human oocytes. Fertil Steril 86: $186-91$.

NEAL MS, ZHU J, FOSTER WG (2008) Quantification of benzo[a]pyrene and other PAHs in the serum and follicular fluid of smokers versus nonsmokers. Reprod Toxicol 25: 100-6.

NEAL MS, ZHU J, HOLLOWAY AC, FOSTER WG (2007) Follicle growth is inhibited by benzo-[a]-pyrene, at concentrations representative of human exposure, in an isolated rat follicle culture assay. Hum Reprod 22: 961-7.

PASZKOWSKI T (1998) Concentration gradient of cotinine between blood serum and preovulatory follicular fluid. Ginekol Pol 69: 1131-6.

PASZKOWSKI T, CLARKE RN, HORNSTEIN MD (2002) Smoking induces oxidative stress inside the Graafian follicle. Hum Reprod 17: 921-5.

PICTON HM, HARRIS SE, MURUVI W, CHAMBERS EL (2008) The in vitro growth and maturation of follicles. Reproduction 136: 703-15.

POLYZOS A, SCHMID TE, PINA-GUZMAN B, QUINTANILLA-VEGA B, MARCHETTI F (2009) Differential sensitivity of male germ cells to mainstream and sidestream tobacco smoke in the mouse. Toxicol Appl Pharmacol 237: 298-305.

POTTS RJ, NEWBURY CJ, SMITH G, NOTARIANNI LJ, JEFFERIES TM (1999) Sperm chromatin damage associated with male smoking. Mutat Res 423: 103-11. 
RAMLAU-HANSEN CH, THULSTRUP AM, AGGERHOLM AS, JENSEN MS, TOFT G, BONDE JP (2007) Is smoking a risk factor for decreased semen quality? A cross-sectional analysis. Hum Reprod 22: 188-96.

RIVELES K, IV M, AREY J, TALBOT P (2003) Pyridines in cigarette smoke inhibit hamster oviductal functioning in picomolar doses. Reprod Toxicol 17: 191-202.

RIVELES K, ROZA R, AREY J, TALBOT P (2004) Pyrazine derivatives in cigarette smoke inhibit hamster oviductal functioning. Reprod Biol Endocrinol 2: 23 .

RIVELES K, TRAN V, ROZA R, KWAN D, TALBOT P (2007) Smoke from traditional commercial, harm reduction and research brand cigarettes impairs oviductal functioning in hamsters (Mesocricetus auratus) in vitro. Hum Reprod 22: 346-55.

ROBBINS WA, VINE MF, TRUONG KY, EVERSON RB (1997) Use of fluorescence in situ hybridization (FISH) to assess effects of smoking, caffeine, and alcohol on aneuploidy load in sperm of healthy men. Environ Mol Mutagen 30: 175-83.

RUBES J, LOWE X, MOORE D, 2ND, PERREAULT S, SLOTT V, EVENSON D, SELEVAN SG, WYROBEK AJ (1998) Smoking cigarettes is associated with increased sperm disomy in teenage men. Fertil Steril 70: 715-23.

SADEU JC, FOSTER WG (2010) Effect of in vitro exposure to benzo[a]pyrene, a component of cigarette smoke, on folliculogenesis, steroidogenesis and oocyte nuclear maturation. Reprod Toxicol.

SALEH RA, AGARWAL A, SHARMA RK, NELSON DR, THOMAS AJ, JR. (2002) Effect of cigarette smoking on levels of seminal oxidative stress in infertile men: a prospective study. Fertil Steril 78: 491-9.

SASSON IM, HALEY NJ, HOFFMANN D, WYNDER EL, HELLBERG D, NILSSON S (1985) Cigarette smoking and neoplasia of the uterine cervix: smoke constituents in cervical mucus. N Engl J Med 312: 315-6.

SCHROEDER AC, EPPIG JJ (1984) The developmental capacity of mouse oocytes that matured spontaneously in vitro is normal. Dev Biol 102: 493-7.

SHEN HM, CHIA SE, NI ZY, NEW AL, LEE BL, ONG CN (1997) Detection of oxidative DNA damage in human sperm and the association with cigarette smoking. Reprod Toxicol 11: 675-80.

SHIVERICK KT, SALAFIA C (1999) Cigarette smoking and pregnancy I: ovarian, uterine and placental effects. Placenta 20: 265-72.

SINKO I, MOROCZ M, ZADORI J, KOKAVSZKY K, RASKO I (2005) Effect of cigarette smoking on DNA damage of human cumulus cells analyzed by comet assay. Reprod Toxicol 20: 65-71.

SMITH CJ, PERFETTI TA, GARG R, HANSCH C (2003) IARC carcinogens reported in cigarette mainstream smoke and their calculated $\log \mathrm{P}$ values. Food Chem Toxicol 41: 807-17.

SOARES SR, MELO MA (2008) Cigarette smoking and reproductive function. Curr Opin Obstet Gynecol 20: 281-91.

SOFIKITIS N, TAKENAKA $\mathrm{M}$, KANAKAS $\mathrm{N}$, PAPADOPOULOS $\mathrm{H}$, YAMAMOTO Y, DRAKAKIS P, MIYAGAWA I (2000) Effects of cotinine on sperm motility, membrane function, and fertilizing capacity in vitro. Urol Res 28: 370-5.

SOKAL RR, ROHLF FJ (1981) Biometry: The Principles and Practice of Statistics in Biological Research. San Francisco: W. H. Freeman and Co.
STILLMAN RJ, ROSENBERG MJ, SACHS BP (1986) Smoking and reproduction. Fertil Steril 46: 545-66.

TALBOT P (2008) In vitro assessment of reproductive toxicity of tobacco smoke and its constituents. Birth Defects Res C Embryo Today 84: 61-72.

THOMPSON J, BANNIGAN J (2008) Cadmium: toxic effects on the reproductive system and the embryo. Reprod Toxicol 25: 304-15.

TIEMANN U, POHLAND R, SCHNEIDER F (1996) Influence of organochlorine pesticides on physiological potency of cultured granulosa cells from bovine preovulatory follicles. Theriogenology 46 : 253-65.

TUTTLE AM, STAMPFLI M, FOSTER WG (2009) Cigarette smoke causes follicle loss in mice ovaries at concentrations representative of human exposure. Hum Reprod 24: 1452-9.

VAN VOORHIS BJ, SYROP CH, HAMMITT DG, DUNN MS, SNYDER GD (1992) Effects of smoking on ovulation induction for assisted reproductive techniques. Fertil Steril 58: 981-5.

VARGA B, ZSOLNAI B, PAKSY K, NARAY M, UNGVARY G (1993) Age dependent accumulation of cadmium in the human ovary. Reprod Toxicol 7: 225-8.

VOGT HJ, HELLER WD, BORELLI S (1986) Sperm quality of healthy smokers, ex-smokers, and never-smokers. Fertil Steril 45: 106-10.

WANG $X$, TAGER IB, VAN VUNAKIS H, SPEIZER FE, HANRAHAN JP (1997) Maternal smoking during pregnancy, urine cotinine concentrations, and birth outcomes. A prospective cohort study. Int J Epidemiol 26: 978-88.

WEIGERT M, HOFSTETTER G, KAIPL D, GOTTLICH H, KRISCHKER U, BICHLER K, POEHL M, FEICHTINGER W (1999) The effect of smoking on oocyte quality and hormonal parameters of patients undergoing in vitro fertilization-embryo transfer. J Assist Reprod Genet 16: 287-93.

WHITTINGHAM DG (1971) Culture of mouse ova. J Reprod Fertil Suppl 14: 7-21.

WOLF DE, HAGOPIAN SS, ISHIJIMA S (1986) Changes in sperm plasma membrane lipid diffusibility after hyperactivation during in vitro capacitation in the mouse. J Cell Biol 102: 1372-7.

YAMAMOTO Y, MAENOSONO S, OKADA H, MIYAGAWA I, SOFIKITIS N (1997) Comparisons of sperm quality, morphometry and function among human sperm populations recovered via SpermPrep II filtration, swimup and Percoll density gradient methods. Andrologia 29: 303-10.

YAUK CL, BERNDT ML, WILLIAMS A, ROWAN-CARROLL A, DOUGLAS GR, STAMPFLI MR (2007) Mainstream tobacco smoke causes paternal germ-line DNA mutation. Cancer Res 67: 5103-6.

YU R, WU M, LIN S, TALBOT P (2006) Cigarette smoke toxicants alter growth and survival of cultured mammalian cells. Toxicol Sci 93: 82-95.

ZHUO L, KIMATA K (2001) Cumulus oophorus extracellular matrix: its construction and regulation. Cell Struct Funct 26: 189-96.

ZITZMANN M, ROLF C, NORDHOFF V, SCHRADER G, RICKERTFOHRING M, GASSNER P, BEHRE HM, GREB RR, KIESEL L, NIESCHLAG E (2003) Male smokers have a decreased success rate for in vitro fertilization and intracytoplasmic sperm injection. Fertil Steril 79 Suppl 3: 1550-4 
